\title{
PRÁTICAS DE COMPREENSÃO AUDITIVA EM LÍNGUA INGLESA POR MEIO DAS TECNOLOGIAS DIGITAIS E DA MÚSICA: UM ESTUDO DE CASO COM ALUNOS DA REDE PÚBLICA DO ENSINO
}

\author{
Gislene Lima Almeida* \\ Cláudia Vivien Carvalho de Oliveira Soares*
}

RESUMO: Neste artigo, analisamos um estudo de caso em que o objetivo principal foi investigar se/como as tecnologias digitais aliadas à música podem contribuir e/ou potencializar a aprendizagem de Língua Inglesa (LI) de alunos do ensino médio da rede pública de ensino, no que se refere à compreensão auditiva de inglês. Desse modo, neste estudo, a qual se insere nos pressupostos da linguística aplicada, e cujos arcabouços metodológicos estão pautados na pesquisa qualitativa, propusemos aos sujeitos uma sequência didática (DOLZ; SCHNEUWLY, 2013) com o gênero música, com vistas à prática da compreensão auditiva através do Lyrics Training, interface digital voltada para a aquisição de línguas por meio da convergência de mídias. Como arcabouço teórico, nos baseamos, principalmente, em Berk (2008), Braga (2007), Leffa (2016), Santaella (2011 e 2014) e Santos e Rossini, (2011).Nessa perspectiva, a análise dos resultados e das observações empreendidas durante todo o período de desenvolvimento do estudo indica que as tecnologias digitais alinhadas a atividades com músicas podem trazer contribuições relevantes para a aprendizagem de inglês ao passo que propiciam a prática de habilidades linguísticas, principalmente no que diz respeito à compreensão auditiva. Ademais, as experiências vivenciadas mostraram que a utilização desses recursos no fazer pedagógico pode significar importantes mudanças para o processo de aprendizagem de LI.

PALAVRAS- CHAVE: Tecnologias digitais; Música; Aprendizagem de Inglês.

\section{Introdução}

A consolidação das novas tecnologias digitais tem provocado diversas mudanças na vida do cidadão contemporâneo. Os aparelhos eletrônicos conectados à internet têm alterado significativamente atividades corriqueiras. A ampla adesão aos recursos digitais pela sociedade atual, especialmente pelos mais jovens, tem levantado questões com relação à utilização dessas interfaces no contexto da aprendizagem de inglês.

Além dos aparatos tecnológicos, há outro recurso que nos conecta com a língua inglesa, e que há muito tem sido incorporado à sala de aula como meio de potencializar o fazer pedagógico: a música.

Atualmente, é possível encontrarmos muitas pesquisas empenhadas em compreender de que forma o ensino e a aprendizagem de língua inglesa poderiam ser incrementados por meio de recursos como a música e as tecnologias digitais (ANJOS-SANTOS et al., 2014; BERK, 2008; LEFFA, 2016; PAIVA, 2010, 2014; SANTAELLA, 2011, 2014). No que se refere aos aparatos digitais, há estudos que sugerem que tais mecanismos oferecem uma infinidade de possibilidades de abordagem da língua, visto que o uso da internet nesse contexto

\footnotetext{
* Mestre em Letras: Cultura, Educação e Linguagens pela Universidade Estadual do Sudoeste da Bahia (Uesb).

** Doutora em Letras pela Universidade Federal da Bahia (Ufba). Professora Titular da Universidade Estadual do Sudoeste da Bahia do Programa de Pós-Graduação em (PPGCEL/UESB).
} 
proporciona, além da comunicação à distância, ferramentas técnicas que dinamizam a produção de textos hipermídia, bem como permitem um amplo acesso a uma quantidade infinita de informações (BRAGA, 2007).

Quanto à utilização da música para aprendizagem de inglês, é sabido que esse recurso, há algum tempo, tem aprimorado a abordagem da língua inglesa de diversas formas. Há, nesse sentido, um acervo relativamente extenso de pesquisas na área que mostram que a música, ao ser incorporada às atividades de estudo do idioma, pode corroborar para a fixação de elementos linguísticos, para a prática da compreensão auditiva e oralidade, memorização de formas gramaticais e lexicais, além de despertar o interesse dos alunos pelo idioma, promover o engajamento dos estudantes nas atividades e transformar a atmosfera da sala de aula em um ambiente mais favorável para a aprendizagem (BERK, 2008; CRUZ, 2004).

Deste modo, este artigo o qual se insere na perspectiva da Linguística Aplicada, discute como as tecnologias digitais aliadas à música podem contribuir e/ou potencializar a aprendizagem de língua inglesa de alunos do ensino médio, no que se refere à compreensão auditiva da língua alvo, por entendermos que a prática do listening (audição) configura-se como um exercício de importância na aprendizagem de uma língua estrangeira. Ressaltamos, ainda, que se trata de um estudo de caso, cujo foco de investigação e análise é uma turma de ensino médio da rede pública de educação do Estado da Bahia, á qual propusemos uma sequência didática (DOLZ; SCHNEUWLY, 2013) com vistas à prática de habilidades de língua inglesa através do Lyrics Training, site gratuitamente disponibilizado na internet, voltado para aprendizagem de línguas por meio da música.

Isto posto, evidenciamos que este texto está organizado em quatro tópicos: no primeiro, apresentamos as implicações das tecnologias digitais para o ensino e aprendizagem de língua inglesa. Apresentamos, também, o Lyrics Training, interface digital investigada neste trabalho. No segundo tópico, tratamos dos aspectos concernentes à música e à inserção desse recurso ao âmbito de aprendizagem de língua inglesa. A terceira seção é dedicada aos aportes metodológicos, abrangência espacial, sujeitos do estudo e instrumentos utilizados no decorrer do processo de investigação. Apresentamos, ainda, a sequência didática proposta aos sujeitos da pesquisa. E, no quarto tópico, por fim, trazemos a análise das atividades propostas e dos resultados das intervenções empreendidas ao longo de todo o trabalho.

\section{Aprendizagem de língua inglesa na era das tecnologias digitais}

Em meio às transformações advindas da emergência das tecnologias digitais, muito se tem discutido sobre seus efeitos na esfera educacional. De acordo com Santaella (2011), o 
desafio da escola atual, é complementar as suas finalidades com as potencialidades do ciberespaço. Conforme a pesquisadora, as tecnologias móveis conectadas à internet trazem a possibilidade de uma educação ubíqua, ou seja, uma aprendizagem disponível a qualquer momento e em qualquer lugar. Além de proporcionar o acesso à informação, essas novas tecnologias permitem a troca de informação e conhecimento entre os estudantes, haja vista a imensidão de recursos de comunicação e redes sociais disponíveis no ciberespaço.

As tecnologias digitais, nesse sentido, afetam as práticas pedagógicas na medida em que possibilitam novas experiências de ensino e aprendizagem a alunos e professores. De acordo com Braga (2007), a internet possibilita a comunicação à distância, propicia ferramentas técnicas que facilitam a produção de textos hipermídia e abre o acesso a um banco de informações potencialmente infinito que se encontra disponível na rede mundial de computadores.

Quanto aos recursos hipermídia do ciberespaço, a autora explica que estes têm um efeito "multiplicador de sentidos", uma vez que a junção de diferentes linguagens (som, imagens, vídeos, texto escrito) e os diferentes significados imbuídos em cada uma dessas modalidades integram-se e complementam-se, auxiliando na interpretação geral de um texto (BRAGA, 2007).

Sobre as ferramentas de busca no ciberespaço, Braga (2007) argumenta que esses recursos têm alterado as relações de poder sobre o conhecimento, visto que, nesse cenário, o professor deixa de ter o monopólio sobre os textos de referência e passa a gerenciar as informações trazidas pelos alunos para a sala de aula. Esse movimento pode acarretar a quebra de hierarquia das estruturas escolares, tornando as instituições de ensino ambientes de aprendizagem mais horizontais. Dessa forma, “os diferentes recursos oferecidos pelas novas tecnologias digitais têm não só viabilizado, mas, principalmente, incentivado propostas de ensino menos centradas no professor e mais voltadas para a interação e o diálogo" (BRAGA, 2007, p. 184).

No que se refere ao ensino e aprendizagem de língua inglesa, podemos dizer que esta tem uma ligação muito consistente com o surgimento e consolidação da cibercultura. A conexão entre ambas foi "reforçada mutuamente pela necessidade e facilidade de comunicação, especialmente após o advento da Internet." (ANJOS- SANTOS et al., 2014, p. 80). Desse modo, a expansão da Internet, além de promover a interação de pessoas ao redor do globo por meio da língua inglesa, favoreceu a emersão de recursos e estudos voltados para a aprendizagem da língua através de interfaces virtuais (BERK, 2008; LEFFA, 2016; PAIVA, 2010, 2014; SANTAELLA, 2011, 2014). 
O advento e popularização das tecnologias digitais e da Internet propiciou, também, a emergência dos Recursos Educacionais Abertos (REAs) (WILEY, 2007 apud LEFFA, 2016). De acordo com Leffa (2016), os REAs são recursos de ensino e aprendizagem, disponibilizados gratuitamente, com uma licença de propriedade intelectual, que podem ser utilizados e adaptados por terceiros. As duas principais características dos REAs, conforme Leffa (2016), são o fato de esses recursos serem de domínio público, e por poderem ser reutilizados e adaptados de acordo com o interesse do usuário.

É pertinente frisar que, neste contexto, entendemos como recurso o instrumento capaz de contribuir para a prática pedagógica. De acordo com Leffa (2016), o recurso, sob esse ponto de vista, "adquire uma importância maior porque potencializa o sujeito, capacitandoo a fazer o que ele seria incapaz de fazer sozinho" (p. 361).

Um conteúdo educacional, nesse sentido, é aquele que provoca um feedback que indica quando o aluno erra e dá dicas de como prosseguir quando o estudante acerta. As possibilidades de ação e interação propiciadas pelas interfaces digitais permitem esse feedback quase que instantaneamente, como afirma Leffa: "Lugares como as redes sociais e principalmente os games, que valorizam a participação e desempenho do usuário, incentivando a ação, e não meramente a recepção, são também lugares de intensa aprendizagem” (GEE, 2004 apud LEFFA, 2016, p. 363).

É necessário considerar, ainda, a importância de iniciativas que visam a formação de professores para a utilização de tecnologias digitais em contextos educacionais. Como exemplo, citamos um projeto, desenvolvido em uma escola pública de Vitória da Conquista, na Bahia (SOARES; ALMEIDA, 2017), cujo objetivo era a promoção do letramento digital de docentes por meio de atividades em ambientes digitais, possibilitando uma ressignificação do fazer pedagógico e da aprendizagem de LI para uma parcela relevante dos sujeitos participantes do projeto.

Ressignificar o ensino e aprendizagem de Língua Inglesa implica, nesse sentido, estar aberto às novas formas de concepção dessa língua e novos modos de trabalhá-la em sala de aula. Em um mundo cada vez mais informatizado, em que os eletroeletrônicos e a internet se tornam cada dia mais popularizados entre jovens e crianças, é preciso lançar o olhar sobre as potencialidades que as tecnologias digitais e as multimídias podem oferecer para as práticas pedagógicas.

Dessa forma, relatamos neste artigo a experiência de um estudo de caso em que propusemos atividades de prática da língua inglesa por meio do Lyrics Training, interface voltada 
para a aprendizagem de línguas através de músicas, com alunos de uma turma de Ensino Médio de uma escola pública, no estado da Bahia.

\section{Lyrics Training}

O Lyrics Training é um software social, gratuitamente disponibilizado na Internet, facilmente acessado pelo link: http://lyricstraining.com/. Consiste em uma interface, cujo objetivo principal é proporcionar o aprendizado de línguas e o aprimoramento das habilidades linguísticas através de vídeos e músicas. O recurso dispõe de músicas de uma infinidade de artistas, cantando em diversos idiomas, para a prática da língua que o usuário objetiva estudar. Dessa forma, ao acessar o site, o estudante visualiza a seguinte página (FIGURA 1):

FIGURA 1: Lyrics Training - Página inicial-

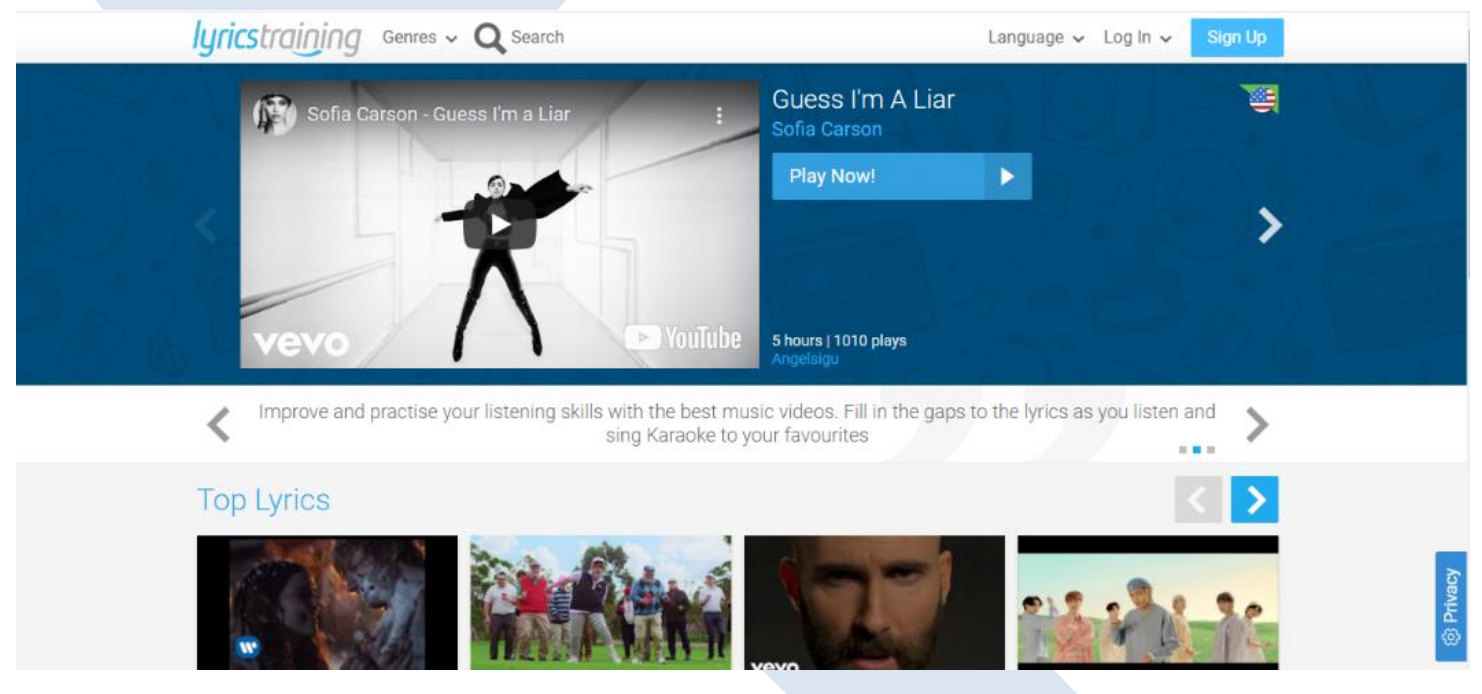

Fonte: capturado pela autora

Após o usuário escolher a música com a qual deseja praticar a língua alvo, o vídeo começa a rodar. Enquanto isso, o aluno deve preencher os espaços vazios com as palavras que faltam na letra da canção. Caso o usuário não complete corretamente cada espaço, a música para e segue somente após o acerto. É possível, ainda, que o estudante volte fases da música quantas vezes considerar necessário.

Enquanto recurso desenvolvido exclusivamente para aprendizagem de línguas, o grande diferencial do Lyrics Training é a possibilidade de convergência de mídias distintas em uma única interface. No processo de prática da língua alvo, o usuário dispõe de recursos sonoros, imagens, vídeos e da língua escrita convergidos em um mesmo espaço. Nesse sentido, as propriedades intrínsecas à interface permitem que o estudante trabalhe a 
compreensão auditiva e a pronúncia das palavras através da música, e ressalta o vocabulário e as características da escrita e da gramática da língua alvo por meio da letra escrita das canções.

O Lyrics Training reúne em um mesmo lugar tecnologias digitais e música. Ambos os recursos fazem parte do cotidiano dessa geração e, quando utilizados para o mesmo fim, neste caso para aprendizagem de inglês, podem trazer importantes colaborações para a construção do conhecimento. Desse modo, na próxima parte do texto, trataremos das propriedades da música e suas implicações para o processo de aprendizagem de língua inglesa.

\section{A música ${ }^{1}$ como instrumento potencializador da aprendizagem de língua inglesa}

A música é uma das formas artísticas mais presentes e importantes na vida do ser humano. Às vezes, nem nos damos conta de que essa arte está inserida em todos os lugares, delineando e regendo situações do nosso cotidiano. No que diz respeito ao ensino, mais precisamente com relação ao ensino e aprendizagem de língua inglesa, a utilização da música para práticas pedagógicas há tempos deixou de ser novidade. Corrobora com esse ponto de vista o extenso volume de trabalhos e publicações na área da Linguística Aplicada (FERRAZ, AUDI, 2013; SANTOS, PAULUK, 2008; VICENTINI, BASSO, 2008, dentre outros) .No contexto da sala de aula de inglês, as letras das músicas e as canções atuam como textos autênticos, isto é, não são textos produzidos com a finalidade de serem trabalhadas em classe, mas são fornecidos diretamente por falantes nativos do inglês, com todas as nuances culturais que envolveram a criação e produção da música. Como explica Cruz (2004, p. 159), ao utilizar canções para estudar a língua inglesa, "os alunos têm a oportunidade de ouvir os falantes nativos da língua alvo. Ao mesmo tempo, eles são expostos a novas culturas através do ponto de vista do letrista" (tradução nossa). Desse modo, ao recorrerem à música como recurso para aprendizagem, o estudante tem acesso às variações da língua em uso, dotada de significados e contextos culturais que, muitas vezes, não são encontrados em determinados textos produzidos especificamente para aulas de inglês.

Além de possibilitar ao educando o contato direto com elementos culturais da língua alvo através de textos autênticos, a música permite ao professor a abordagem da

\footnotetext{
${ }^{1}$ De acordo com Cruz (2004), música, letra e canção possuem conceitos diferentes. Conforme a autora, as letras (lyrics) são as palavras da canção, já a música é o som da voz ou de instrumentos combinados harmoniosamente. As canções, por fim, são história ou palavras que são cantadas.

2 "Students have the opportunity to listen to native speakers of the target language. At the same time, they are exposed to new cultures through the lyricist's point of view" (CRUZ, 2004. p. 159).
} 
compreensão auditiva, da oralidade, da leitura e da escrita. No que diz respeito à compreensão auditiva (listening) e a oralidade (speaking), Vicentini e Basso (2008) asseveram que

\begin{abstract}
ao explorarmos a música, a acuidade auditiva melhora a percepção dos alunos na atividade de "listening", e consequentemente a produção oral. Estas duas habilidades, de acordo com os alunos, são as habilidades mais difíceis para se desenvolver. O reconhecimento sonoro das palavras contidas nas letras das músicas leva o aluno a pronunciá-las de forma mais correta. Fazer com que o aluno entenda o significado das palavras de acordo com o contexto da música contempla a construção do conhecimento, fazendo com que os educandos possam refletir sobre a mensagem da música tornando-a significativa (VICENTINI; BASSO, 2008, p. 6).
\end{abstract}

Desse modo, o listening configura-se como um exercício importante para a aprendizagem da língua inglesa, visto que através da audição o aluno recepta e internaliza informações sem as quais não poderiam produzir em uma língua, como os fatores linguísticos, pronúncia, entonação, dentre outros. O que ouvimos funciona, nesse sentido, como input, e, para que esses insumos sejam de fato compreendidos e armazenados, é necessário um trabalho que torne o processo de aprendizagem significativo (BROWN, 1987 apud MESTI; BASSO, 2008).

Tornar a prática de compreensão auditiva de fato significativa implica muito mais do que simplesmente trazer para sala de aula áudios com falantes da língua alvo. A discussão dos aspectos culturais que envolvem o material auditivo é muito relevante para que o aprendiz compreenda os significados do que se ouve como um todo. Conforme Mendes (2008), é essencial que o educador seja culturalmente sensível, ou seja, "é necessário incentivar os aprendizes a reconhecer a língua em suas especificidades não só formais, mas, sobretudo, culturais e contextuais, e também reconhecer-se nela, como sujeito histórico e encaixado em experiências de ser e agir através da língua” (p. 63). Nesse cenário, a música pode contribuir sobremaneira, dado que se trata de uma expressão artística ricamente dotada de aspectos culturais e contextuais.

Além desses benefícios, os recursos musicais contribuem, ainda, para a memorização da língua alvo. Santos e Pauluk (2008), conforme Murphey (1992), explicam que a música, por diversos motivos, se fixa em nossa mente, tornando-se parte de nós. Ela "educa nosso ouvido incentivando-nos a escutar, repetir e até cantá-las" (p. 9). Gfeller (1983 apud VICENTINI; BASSO, 2008) afirma que música, através do ritmo, fornece instrumentos para que nosso cérebro possa memorizar aspectos da língua que estamos aprendendo:

\footnotetext{
a música e seu sub componente, o ritmo, tem beneficiado a rota do processo de memorização. Estudos têm provado que quando vários tipos de informações verbais (por exemplo: tabuadas, regras ortográficas) foram apresentadas simultaneamente com música a memorização foi significativamente melhor. A música aumenta a rota de memorização através do ritmo (p. 7).
} 
Outro fator que torna a música um recurso relevante para o fazer pedagógico é que ela é de fácil acessibilidade, e com surgimento e popularização das tecnologias digitais e da internet, o acesso a músicas tornou-se ainda maior. Atualmente, é possível encontrar e baixar da internet qualquer música que queiramos. Há inúmeros aplicativos e interfaces de músicas para ouvir online, sites exclusivos de videoclipes, rádios online, e toda uma gama de possibilidades de acesso a qualquer música, em qualquer lugar.

As facilidades da internet propiciaram, também, o aparecimento de sites, softwares e aplicativos voltados para a aprendizagem de línguas através de músicas, como é o caso do Lyrics Training, interface que abordamos neste trabalho. Entretanto, antes de apresentarmos os resultados obtidos com a realização das atividades na referida interface, é necessário designar a metodologia, os sujeitos e materiais que nos nortearam na realização desta pesquisa.

\section{Caminhos metodológicos}

O presente estudo que se insere no domínio das Ciências Sociais, cujos sentidos de investigação se alicerçam nos seres humanos, nos significados e intencionalidades que os indivíduos e os grupos sociais dão às suas ações, guia-se, fundamentalmente, pelos pressupostos da pesquisa qualitativa, isto é, objetiva estudar, compreender e enfatizar os fenômenos sociais, as atitudes, aspirações e significações concernentes aos sujeitos da investigação (FLICK; 2008; MINAYO, 2001; ANDRÉ, 2005, 2008).

Desse modo, enfatizamos que a pesquisa foi realizada em um colégio público estadual, localizado na zona oeste, região periférica da cidade de Vitória da Conquista, Bahia. Como sujeitos participantes da investigação, contamos com a colaboração de quatorze estudantes de uma turma do $1^{\circ}$ ano do Ensino Médio da referida escola. Os sujeitos da pesquisa, que participaram voluntariamente, foram informados sobre o teor e finalidade do estudo e assinaram o TCLE ${ }^{3}$ (Termo de Consentimento Livre e Esclarecido) antes do início do processo de investigação.

Como instrumentos de geração de dados, propusemos aos estudantes participantes uma sequência didática (doravante SD). A SD, cujos mentores são os linguistas Dolz e Schneuwly (2013), é um conjunto de atividades de cunho pedagógico, sistematizado, que tem

\footnotetext{
${ }^{3}$ Este estudo está identificado pelo protocolo 56519116.5.0000.005 do Certificado de Apresentação para Apreciação Ética (CAAE), e recebeu aprovação do CEP/UESB para prosseguimento de suas atividades.
} 
como fim a abordagem de algum gênero textual ${ }^{4}$ oral ou escrito. O objetivo da SD é o desenvolvimento das capacidades linguísticas e textuais dos estudantes, através de uma sucessão de atividades e de exercícios que buscam aprimorar o entendimento dos alunos acerca de um gênero textual.

Destarte, apresentamos uma proposta de sequência didática, desenvolvida para ser trabalhada em sete aulas, junto aos participantes desta pesquisa. As questões sugeridas circulam em torno do gênero música. Assim, a canção selecionada para esta SD foi "Mercy" (https://youtu.be/KkGVmN68ByU), do cantor canadense Shawn Mendes.

Assim, as atividades da SD foram organizadas da seguinte forma: (I) Apresentação da Situação, quando foram apresentados o projeto e a interface Lyrics Training aos alunos participantes e à professora regente de inglês; (II) Produção Inicial, quando os alunos foram encaminhados ao laboratório da escola para realizar, pela primeira vez, a atividade de prática de compreensão auditiva no Lyrics Training com a música 'Mercy'; (III) Módulo I- Compreendendo o contexto da música, quando foi realizada a leitura da letra da música "Mercy" e a apresentação e discussão do videoclipe da referida canção, em que o objetivo da atividade era a interpretação da canção através da assimilação da letra com as cenas do vídeo; (IV) Módulo II- Enriquecendo o vocabulário, quando foram propostas as atividades de identificação de cognatos e falsos cognatos e de Palavras-Cruzadas. Buscamos, neste módulo, ampliar o vocabulário de língua inglesa dos estudantes, por meio do reconhecimento dos vocábulos já conhecidos e da aquisição de palavras supostamente desconhecidas pelos alunos; (V) Módulo IIIPraticando o Listening, em que os estudantes realizaram uma atividade de compreensão auditiva, organizando frases da música "Mercy", de acordo com a sequência da canção; (VI) Módulo IV-Cantando, quando os alunos, juntamente com a pesquisadora, traduziram e cantaram a música em questão, praticando, assim, o speaking e encerrando as atividades dos módulos; Produção Final, no momento final da SD, quando os estudantes foram conduzidos novamente ao laboratório de informática da escola para realizarem a atividade de compreensão auditiva no Lyrics Training, com a mesma música do início do estudo.

Por se tratar de uma pesquisa qualitativa, a observação participante constitui-se como um dos principais procedimentos de geração de dados adotados neste estudo, isto é, a pesquisadora esteve presente em todas as aulas no decorrer de pesquisa, embora não fosse professora regente da turma, observando, registrando em forma de anotações, fotos e filmagens os sujeitos participantes, o comportamento, as ações e reações do grupo quanto às atividades

\footnotetext{
${ }^{4}$ Entendemos gêneros textuais como "forma de enunciados (orais e escritos) concretos e únicos, que emanam dos integrantes duma ou outra esfera da atividade humana” (BAKHTIN, 2000: 279).
} 
da SD e à plataforma Lyrics Taining. Além disso, os alunos participantes responderam, ao término da pesquisa, a um questionário onde explicitaram suas impressões e avaliações acerca das atividades da SD e da interface Lyrics Training. O material gerado foi rigorosamente analisado durante e ao final da investigação.

Vale ressaltar, ainda, que a plataforma digital utilizada conta com um sistema de pontuação. Assim, foi possível observar na Produção Inicial e na Produção Final a diferença de desempenho dos estudantes no que se refere à utilização do Lyrics Training, no início e no fim do processo.

Nessa perspectiva, para efeito desse artigo, apresentamos abaixo uma discussão em torno dos dados gerados e analisados no que se refere à prática do listening.

As tecnologias digitais e a música como potencializadoras da aprendizagem de língua inglesa

Ao iniciarmos o projeto, reunimos os estudantes para a "Apresentação da Situação", quando esclarecemos os objetivos das atividades que ocorreriam e que comporiam a sequência didática, nas aulas subsequentes. $\mathrm{Na}$ aula seguinte, os alunos realizaram a "Produção Inicial" com o Lyrics Training, quando foram conduzidos ao laboratório de informática da escola para praticarem, pela primeira vez, a língua alvo na referida interface, utilizando, como esclarecido anteriormente, a música "Mercy", do cantor canadense Shawn Mendes.

As observações da Produção Inicial revelaram algumas dificuldades em compreender o que era dito na música trabalhada. Desse modo, no módulo III, propusemos atividades de listening para que os estudantes praticassem e melhorassem a compreensão auditiva, haja vista que, na prática desse tipo de atividade, o aluno recepta e internaliza informações, como os fatores linguísticos, pronúncia, entonação dentre outros. A aula que correspondeu a esse módulo teve a duração de 1 hora e 20 minutos, tempo utilizado para correção dos exercícios do módulo anterior e para a atividade de escuta. Nesse sentido, foi requisitado aos estudantes que se reunissem em grupos. Como, nesse dia compareceram à aula 12 alunos, 4 grupos de 3 discentes foram formados. Foram entregues a cada grupo uma cópia da música "Mercy", com espaços em branco, para que eles pudessem encaixar as frases que haviam sido retiradas da letra. Assim, a música foi executada através de um pen drive acoplado a uma caixinha de som, para que os alunos pudessem organizar as frases enquanto a ouviam, sendo executada diversas vezes, até que todos os grupos conseguissem finalizar a atividade.

Percebemos, nesse módulo, um engajamento por parte dos alunos. O envolvimento e o esforço dos estudantes para ouvirem a música e realizarem a atividade eram perceptíveis. 
Ao final da aula, todos os grupos haviam realizado a atividade com sucesso, com quase todas as frases organizadas corretamente. Esses dados nos mostram, mais uma vez, que a música é um recurso capaz de modificar a rotina e a atmosfera da sala de aula, despertando no aluno o interesse e a atenção para as práticas pedagógicas corroborando para a afirmação de Berk (2008), que pontua que a música em sala aula gera, dentre muitas atitudes, uma conexão entre os estudantes, e entre os estudantes e os instrutores.

No questionário, que foi realizado após a produção final, procuramos saber dos participantes com quais módulos eles mais se identificaram. Das opções apresentadas, a que os estudantes mais se mencionaram foi justamente a atividade em que eles encaixavam as frases da música "Mercy". Do total de doze alunos, nove apontaram para tal exercício, testificando o que foi observado durante a execução do módulo III. Os dados assinalam, ainda, que os exercícios que fogem do padrão de aula de LI, em que o foco é a abordagem da estrutura da língua, podem incrementar o processo de aprendizagem, tornando-o mais dinâmico e envolvente.

Os participantes foram sondados, também, sobre de que forma as atividades supracitadas colaboraram no que se refere à habilidade de compreensão auditiva da língua inglesa. Questionamos se os exercícios desenvolvidos nos módulos facilitaram o entendimento do que é dito na música, e se melhoraram o desempenho dos alunos na realização da Produção Final, no Lyrics Training.

Destarte, oito dos doze estudantes assinalaram que as atividades facilitaram a compreensão auditiva e a evolução no desempenho dos participantes no Lyrics Training, se comparado à Produção Inicial. De acordo com a análise dos dados, as atividades no módulo colaboraram para a construção dos sentidos presentes na música, introduziu novos termos em língua inglesa no vocabulário dos sujeitos participantes e melhorou a compreensão dos alunos quanto à língua falada. Tais constatações nos remetem a Mesti e Basso (2008), que nos elucidam acerca dos insumos que podem ser internalizados por meio da prática de compreensão auditiva. No caso deste estudo, compreendemos que os exercícios de listening, através da escuta da canção, tornaram os alunos mais familiarizados com o léxico e preparados para ouvir e compreender o que estava sendo cantado.

De acordo com as observações, ao realizarem a atividade no Lyrics Training, os estudantes clicavam menos de forma aleatória e demonstravam mais segurança na realização da atividade. Corroboram com essas asserções a pontuação obtida na Produção Final. Desse modo, enquanto na Produção Inicial a média era de 40 erros, na Produção Final esse número cai para 20 erros, o que indica uma evolução na compreensão auditiva e na identificação de 
vocábulos da língua. Entendemos, aqui, o que diz Leffa (2016) a respeito do feedback que obtemos com a "gameficação" dos recursos digitais voltados para a educação, uma vez que os participantes puderam observar quase que instantaneamente a evolução, os erros e os acertos durante a atividade no Lyrics Training.

Com relação à visão dos participantes acerca do emprego dos recursos musicais no contexto da aprendizagem LI, interpelamos os estudantes a respeito das possíveis contribuições da música para o estudo da língua inglesa. Perguntamos em que medida a música pode colaborar para aprendizagem de inglês. Foram dadas as seguintes opções: a) aprender novo vocabulário; b) melhorar a compreensão auditiva da língua inglesa; c) ler; d) escrever em inglês; e) treinar a fala; f) aprender um pouco sobre a cultura dos países de língua inglesa; g) não ajuda em nada; e h) outros. Podendo o aluno assinalar mais de uma alternativa.

Assim, quatro alunos afirmaram que a música pode contribuir para aprendizagem de vocabulário; oito disseram que melhora a compreensão auditiva da língua inglesa; dois alunos assinalaram que contribui para leitura; quatro ressaltaram que a música colabora para a escrita em inglês; oito apontaram que canções podem colaborar com o treino da fala (speaking); e dois afirmaram que a música corrobora para aprendizagem sobre aspectos culturais de países de língua inglesa. As alternativas (g) "não ajuda em nada" e (h) "outros" não foram assinaladas. Nessa perspectiva, na concepção dos sujeitos, a abordagem da LI por meio de música pode auxiliar, principalmente, na melhoria da compreensão auditiva e da habilidade oral. Entendemos, assim, que o processo de ouvir a música e tentar cantá-la pode enriquecer essas práticas. Ademais, devemos ressaltar a capacidade que a música oferece para o processo de memorização da língua, dado que quase todos disseram ter aprendido a palavra "Mercy", repetida várias vezes no refrão da canção, denotando que, conforme Murphey (1992, apud SANTOS; PAULUK, 2008), a música, por diversos motivos, se fixa em nossa mente, tornando-se parte de nós. Ela "educa nosso ouvido incentivando-nos a escutar, repetir e até cantá-las" (p. 9).

No questionário, tecemos, também, questões acerca da interface Lyrics Training, mais propriamente. Questionamos aos estudantes se eles utilizaram a interface fora da escola e se buscaram trabalhar com outras músicas além da canção apresentada na atividade desenvolvida. Para a primeira pergunta, sete alunos afirmaram ter acessado a interface fora do colégio, e cinco disseram não ter acessado. Desse montante, dois participantes disseram ter praticado outras músicas.

Os participantes foram indagados, ainda, se consideravam o Lyrics Training uma interface capaz de favorecer a prática das habilidades linguísticas. Nessa perspectiva, seis alunos 
assinalaram que o Lyrics Training pode auxiliar o estudante a aprender novos vocábulos, nove concordaram que a interface ajuda na compreensão auditiva e seis afirmaram que o recurso pode colaborar para que o processo de escrita correta dos vocábulos em inglês. Entendemos, assim, com base na análise das respostas, que os participantes enxergam no Lyrics Training um recurso que pode contribuir para o processo de aprendizagem de inglês, principalmente no que diz respeito à compreensão oral.

Além do mais, em um diálogo com um dos discentes, ficou claro que o vídeoclipe o ajudou no entendimento do contexto da música, corroborando com o pressuposto de que o Lyrics Training possui a vantagem de convergir diversas mídias em uma única interface. Desse modo, o aprendiz conta com os recursos sonoros da música, com as imagens e cenas dos videoclipes e com a língua escrita das letras das canções. Esses recursos hipermidiáticos, utilizados concomitantemente, contribuem para a aprendizagem da língua alvo ao passo que permite ao usuário reconhecer, não somente as especificidades formais da língua, mas os contextos e os cenários culturais em que as canções se desenvolvem por meio da assimilação de som, imagens e língua escrita, o que resulta na aprendizagem significativa da língua (MENDES, 2008).

Por fim, os participantes foram convidados a avaliarem a interface Lyrics Training, deixando claro que queríamos ouvir a sincera opinião deles, inclusive críticas, caso houvesse. Nesse sentido, quase todos os estudantes avaliaram positivamente a interface. Apenas um estudante disse não estar apto a opinar, pois não entende de computadores. Assim, apresentamos, a seguir, excertos dos relatos dos estudantes quanto à interface Lyrics Training:

\begin{tabular}{|c|l|}
\hline A. 06 & $\begin{array}{l}\text { Tipo, eu sou de escola pública e, tipo, eu nunca vi isso acontecer, e o Lyrics Training ajudou muitas pes- } \\
\text { soas a dialogar (sic) o inglês. Assim como eu, que hoje pratico não por obrigação, mas sim por mim (sic) } \\
\text { identificar com esse projeto [...] }\end{array}$ \\
\hline A. 05 & $\begin{array}{l}\text { Na minha opinião, eu achei muito bom, porque nos ajudou muito a identificar algumas palavras que } \\
\text { não sabemos. }\end{array}$ \\
\hline A. 11 & Ótimo, comecei a entender algumas coisas que tinha muita dificuldade em interpreta (sic). \\
\hline
\end{tabular}

Os relatos, as observações e os números aqui apresentados nos dão uma noção, mas, certamente, não exprimem as verdadeiras proporções que essas atividades tomaram na vida de alguns desses sujeitos. As conversas que tivemos com alunos nos intervalos das atividades pressupõem que essas intervenções podem ter gerado resultados que vão muito além do que foi possível de ser observado durante o desenvolvimento das atividades. Um dos estudantes, por exemplo, expôs que havia realizado a atividade do Lyrics Training em casa, juntamente com um membro de sua família, que também se interessou pela interface, pretendendo 
utilizá-la outras vezes. Esse mesmo aluno alegou que, com o Lyrics Training, é melhor para aprender a língua. "Melhor que na sala", assegurou $A$. 06. Tal afirmação nos remete a Santaella (2014) e suas ponderações acerca de uma educação ubíqua, que extrapola os muros das escolas, podendo ocorrer em qualquer lugar, a qualquer momento e de diversas formas. Entendemos assim, que o Lyrics Training pode colaborar, de certa forma, para a fluidez do processo de ensino e aprendizagem no que se refere à aquisição da língua alvo.

O relato supracitado foi interrompido por outro discente, o qual afirmou que a interface colabora para a assimilação da pronúncia, uma vez que propicia a união da língua escrita com língua oral, permitindo que o estudante se atente também para a pronúncia dos termos. Nesse sentido, nas atividades do Lyrics Training, o insumo (ou input) é a língua oral materializada através da música que, além da compreensão auditiva, abrange a prática de modalidades como oralidade, pronúncia, leitura e escrita (CRUZ, 2004).

\section{Considerações finais}

Em relação à compreensão auditiva, consideramos que o trabalho sistematizado da língua desenvolvido em módulos da sequência didática foi importante na medida em que proporcionou a prática do listening, tornando melhor a compreensão do que era cantado na canção adotada nesta pesquisa. Assim, acreditamos que as tecnologias digitais podem contribuir para a aprendizagem de língua inglesa de diversas maneiras, embora a abordagem da língua proposta pela SD mostre que o trabalho sistematizado da língua alvo fornece o input necessário para o exercício da compreensão auditiva.

Inferimos, neste trabalho, que o papel da escola e dos professores como norteadores para a construção do conhecimento no âmbito do ciberespaço é deveras importante. Conforme Santos e Rossini (2011), endossamos que é necessária a mediação do professor no que diz respeito à aprendizagem no ciberespaço. Sem um trabalho pedagógico bem delineado as interfaces digitais podem representar meros recursos para o armazenamento de dados.

Nessa perspectiva, levando em consideração as contribuições da abordagem sistematizada da língua, contidas nas atividades dos módulos, concluímos que os aspectos digitais que caracterizam o Lyrics Training (convergência de mídias, mobilidade, gamificação etc.) contribuíram para a aprendizagem de LI dos estudantes ao surgir como uma alternativa de prática da língua. A característica de game, intrínseca à interface, apresentou-se a eles como uma forma divertida e dinâmica de aprender inglês que, conforme relatos e observações, se mostrou diferente das abordagens "tradicionais" da língua, com as quais os alunos estão 
familiarizados, motivando-os a estudar idioma de forma mais autônoma (relembramos, aqui, os alunos que realizaram as atividades no Lyrics Training em casa).

No que se refere às contribuições da música para aprendizagem de LI dos sujeitos da pesquisa, entendemos que, além dos inputs internalizados pelos estudantes através da escuta da canção trabalhada, e da evolução da compreensão auditiva, as músicas em sala de aula proporcionaram uma atmosfera agradável e envolvente ao ambiente, tornou as aulas mais lúdicas, despertou o interesse de grande parte dos sujeitos pelas atividades de língua inglesa, e fez emergir, de certo modo, o interesse dos estudantes em compreender a língua.

\title{
PRATICES OF LISTENING COMPREHENSION IN ENGLISH LANGUAGE THROUGH DIGITAL TECHNOLOGIES AND MUSIC: A CASE STUDY WITH STUDENTS FROM THE PUBLIC SCHOOL SYSTEM
}

\begin{abstract}
In this article, we analyzed a case study which the main objective is to investigate if/how digital Technologies allied to musiccan contribute and/or enhance the English language learning of high school students in the public school system, concerning to listening comprehension. Thus, in this study, which is inserted in the presuppositions of applied linguistics, and whose methodological frameworks are based on the qualitative research, we propose to students a didactic sequence(DOLZ, SCHNEUWLY, 2013) with the music genre, with a view to listening comprehension practice through "Lyrics Training", a digital interface focus on languages acquisitiont hrough the convergence of media. As a theoretical framework, we rely mainly on Berk (2008), Braga (2007), Leffa (2016), Santaella (2011 and 2014) and Santos and Rossini, (2011).Thereby, the analysis of the results and the observations made throughout the study's development period indicates that virtual Technologies aligned to music activities can bring relevant contributions to the English learning, while allowing the practice of language skills, especially regarding to hearing comprehension. Furthermore, the experiences showed that the use of these resources in the classroom can mean important changes to the learning process.
\end{abstract}

KEYWORDS: Digital technologies; Music; Learning English.

\section{REFERÊNCIAS}

ANDRÉ, M. E. D. A. Etnografia da prática escolar. 14. ed., Campinas: Papirus, 2005. . Estudo de caso em pesquisa e avaliação educacional. Brasília: Liber Livro, 2008.

ANJOS-SANTOS. L. M; GAMERO. R; GIMENEZ. T. N. 2014. Letramentos digitais, interdisciplinaridade e aprendizagem de língua inglesa por alunos do Ensino Médio. Trabalhos em Linguística Aplicada, Campinas, n (53.1): 79-102

BRAGA, D. B. Práticas Letradas digitais: Considerações sobre possibilidades de Ensino e de reflexão social crítica. In: J. C. ARAÚJO, Internet e ensino, novos gêneros, outros desafios. Rio de Janeiro: Lucerna, 2007, p. 181-195.

BERK, R. A. Music and music technology in college teaching: Classical to hip hop across the curriculum. Disponível em: <http://www.ronberk.com/articles/2008_music.pdf $>$ Acessoem: 20/11/2016.

CRUZ, G. F. The power of music and songs in and out of the language classroom. In: D. C. LIMA, Foreign-language learning and teaching: from theory to practice. Vitória da Conquista: Edições UESB, 2004. p. 157- 178. 
DOLZ , J; SCHNEUWLY, B. Gêneros orais e escritos na escola. 3. ed., Campinas: Mercado de Letras, 2013. 240 p.

FERRAZ. M; AUDI. L. C.C. Ensino de Língua Inglesa com música. Revista eletrônica Pródocência/UEL. Disponível em: < http://www.uel.br/revistas/prodocenciafope>Acessoem: 10/11/2016.

FLICK, U. Introdução à pesquisa qualitativa. 3. ed. Porto Alegre: Artmed, 2008.

LEFFA, J. V. Uma outra aprendizagem é possível: colaboração em massa, recursos educacionais abertos e ensino de línguas. Trabalhos em linguística aplicada. Campinas, n(55.2), p. 353-377, 2016.

MENDES, E. Língua, Cultura e formação de Professores: por uma abordagem de ensino Intercultural.In: E. MENDES; M. L. S. CASTRO (orgs), Saberes em português: ensino e formação docente. Campinas: Pontes Editores, 2008. p. 57-77.

MESTI, V. L; BASSO, R. A. A. Proposta de atividades de "listening" para melhorar e desempenho e desenvolver a habilidade de ouvir inglês. Trabalho desenvolvido no Programa de Desenvolvimento Educacional (PDE) da Secretaria de Educação do Estado do Paraná. Disponível em <http://www.diaadiaeducacao.pr.gov.br/portals/pde/arquivos/2298-8>. Acessoem: 05/12/2016.

MINAYO, M. C. S. O. Pesquisa social. Teoria, método e criatividade. 18. ed. Petrópolis: Vozes, 2001.

MURPHEY,T. Music \& Song. Oxford: Oxford University Press, 1990.

PAIVA, V.M. L. de O. O. Propiciamento (affordance) e autonomia na aprendizagem de língua inglesa. In: D. C. LIMA, Aprendizagem de língua inglesa: histórias refletidas. Vitória da Conquista: Edições UESB, 2010. Disponível em: <http://www.veramenezes.com/affordance.pdf.>Acessoem: 27/07/2016.

- O uso da tecnologia no ensino de línguas estrangeiras: breve retrospectiva histórica. Disponível em < http://www.veramenezes.com/techist.pdf>Acessoem: 10/05/2016.

SANTOS, E; ROSSINI, T. A realidade virtual na educação online: novas possibilidades de expressão e comunicação. Revista Tecnologia Educacional. São Paulo. V. 31, p. 59-75, 2011.

SANTAELLA, L. Educação tradicional e educação ubíqua. Disponível em <https://www.youtube.com/watch?v=gvhAmHXtESE>Acessoem: 06/06/2016.

Gêneros discursivos híbridos na era da hipermídia / Hybrid Discursive Genres in the Hypermedia Era. São Paulo, Bakbtiniana, 2014. p. 206-216.

SANTOS, J. F.; PAULUK, I. Proposições para o ensino de língua estrangeira por meio de músicas. Disponível em: <http://www.diaadiaeducacao.pr.gov.br/portals/pde/arquivos/752-4.pdf > . Acesso em: 02/12/2016.

SOARES, C. V. DE O.; ALMEIDA, G. L, Praticas de letramento digital no contexto de formação continuada de professores. In: XXVI Jornada do Grupo de Estudos Linguísticos do Nordeste, Recife, 2017. Anais Eletrônicos da XXVI Jornada do Grupo de Estudos Linguísticos do Nordeste, Recife, PE. Pipa Comunicação, Caderno 08, p. 609-620.

VICENTINI, C. T.; BASSO, R. A. A. 2008. O ensino de inglês através da música. Disponível em: <http://www.diaadiaeducacao.pr.gov.br/portals/pde/arquivos/2293-8.pdf>.

Acessoem: 02/12/2016.

Recebido em: 15/11/2020.

Aprovado em: 16/01/2021. 